\title{
La trayectoria narrativa de Mercedes Formica (1913-2002): mujer, posguerra y compromiso
}

\author{
Miguel Soler Gallo \\ Universidad de Salamanca \\ miguel.soler@usal.es \\ https://dx.doi.org.10.12795/futhark.2020.i15.12
}

Fecha de recepción: 17.03.2020

Fecha de aceptación: 5.05 .2020

Resumen: En este trabajo se efectúa un recorrido por la trayectoria literaria de Mercedes Formica, narradora española perteneciente a la denominada "Generación del 36". Su obra, poco conocida y desarrollada en gran parte durante la posguerra española, constituye un ejemplo de compromiso con su realidad y de preocupación por los seres en conflicto con sus circunstancias.

Palabras clave: escritora, trayectoria, generación del 36, posguerra, compromiso.

\section{The narrative trayectory of Mercedes Formica (1913- 2002): women, postwar period and commitment}

\begin{abstract}
In this work a journey through the literary career of Mercedes Formica, a Spanish narrator belonging to the so-called "Generation of 36", is made. Her work, little known and developed largely during the Spanish postwar period, is an example of commitment to her reality and concern for beings in conflict with their circumstances.
\end{abstract}

Keywords: writer, trajectory, generation of 36, postwar, commitment.

Sumario: I. Introducción. 2. El florecimiento de las mujeres escritoras durante la posguerra. 2.I. La realidad, el compromiso: el itinerario narrativo de Mercedes Formica. Conclusiones. 


\section{Introducción}

En el panorama narrativo español de posguerra se encuadra la trayectoria de Mercedes Formica (Cádiz, 1913 - Málaga, 2002). La autora pertenece a la denominada Generación del 36, con ella se identificaba y la reivindicaba como grupo independiente del 27 y del 50 . El estallido de la Guerra Civil, que le sorprende con 23 años, si no es el elemento crucial, es el punto de inflexión de su vida y de la de muchos coetáneos. Homero Serís, en 1945, señalaba la contienda como el hito histórico de esta generación, de la misma forma que la guerra contra Estados Unidos y la pérdida de los últimos territorios de Ultramar, determinaron la formación de la Generación del 98. El concepto de "generación" es muy discutido y un ejemplo de ello es lo que sucede con la Generación del 36, sobre la cual la crítica aún debate su existencia. A exponer razones a favor o en contra dedicó la revista Ínsula un número extraordinario (224-225) en 1965, que resulta imprescindible para profundizar en la cuestión'. Como decimos, la Guerra Civil es el acontecimiento que marca a fuego a este grupo de escritores, pero no como preocupación intelectual, sino que posee un sentido de dolor, persecución, muerte y destrucción de cualquier ideal político. Eran demasiado jóvenes [en 1936] para tener que ser tan mayores en 1939, como dejó escrito Guillermo Díaz Plaja en el ensayo Memoria de una generación destruida (1966), convencido también de formar parte de ella. Generación "destruida" porque, desde entonces, surgieron dos bandos, los vencedores y los vencidos. Por su parte, Ricardo Gullón definía esta generación, en el citado número de Ínsula, como "perdida" y "fracasada", "machacada" y "sacrificada" (1965: I).

$\mathrm{Si}$ durante la dictadura franquista, en el ámbito cultural, fueron los vencedores quienes gozaron de presencia y proyección en España, tras ella fueron desfilando progresivamente por la fría pasarela del olvido. Andrés Trapiello describía esta situación con una frase que es imprescindible recordar cuando se aborda este período: "Los que ganaron la guerra perdieron los manuales de literatura" o "Los que perdieron la guerra ganaron los manuales de literatura". Del mismo autor, conviene consultar su famoso ensayo Las armas y las letras: literatura y Guerra Civil (1936-1939), para comprender la literatura del período. Esta es la singularidad de la llamada Generación del 36, que se atiende a un "lado" en relación con el "otro", normalmente, en términos de "buenos" y "malos". Por eso, Mercedes Formica aclamaba al finalizar Visto y vivido, el primer tomo de sus memorias, publicado originalmente en 1982, que "el gran problema de la generación del 36 es un problema de olvido; que alguien explique a uno y a otro bando que olvidar no es sinónimo de traición" (2020: 303)².

\footnotetext{
I Para más datos de la Generación del 36, aunque orientada a la poesía, pueden consultarse los trabajos de Jaime Ferrán y Daniel P. Testa (1973) y García de la Concha (1987).

${ }^{2}$ Formica dejó un legado de tres tomos de memorias: Visto y vivido (1982), Escucho el silencio (1984), ambos en la editorial Planeta, y Espejo roto. Y espejuelos (1998), en Huerga y Fierro editores. En 2020, la 
Vencedores hubo acérrimos en su victoria hasta el final de sus días, por supuesto, pero hay que contemplar a los que se vieron colocados en esta posición por haber simpatizado o militado, antes de la contienda, en opciones políticas distantes de la República, y que, el 18 de julio de1936, cada cual con sus circunstancias, iban entendiendo que el denominado "bando nacional" era "el de ellos". Es decir, entre los vencedores existieron también discrepancias ideológicas, $y$, entre los que hicieron la guerra ataviados, por ejemplo, de azul falangista, hubo quienes no creían que de una guerra pudiera emerger una "Nueva España", o quienes, habiendo acogido el conflicto bélico de forma apasionada en un primer momento, se percataron después de su error. A estos que al finalizar el conflicto se les marcó con la etiqueta de "vencedores", sin haberse sentido exultantes con ese "triunfo", les arribó antes o después un aspecto que terminó englobándolos: el desencanto. $Y$ un hecho histórico puso en marcha ese estado de ánimo: el decreto de unificación de abril de 1937, estrategia necesaria para que el general Francisco Franco ganara la guerra y se presentase, a la manera fascista, como jefe del Estado Nuevo (Payne, 1997). Es evidente que el fusilamiento de José Antonio Primo de Rivera, líder del movimiento Falange Española ${ }^{3}$, por parte del gobierno republicano, el 20 de noviembre de 1936, produjo en un buen número de falangistas de primera hora, auténticos o "camisas viejas", aquellos que no se veían representados después del citado decreto, desazón, congoja y "desnortamiento", pero esta sensación ya se estaba macerando desde el momento de su detención y encarcelamiento, pues la noticia de la muerte llegaba de forma confusa $y$, aun después de finalizar la Guerra Civil, se dudaba de su certeza. Lo que no implica que, cuando hicieron el relato de sus vidas, estos "desencantados" pusieran como origen de su evolución ideológica el fusilamiento del líder, como fue el caso de Mercedes Formica, quien reconoció que su implicación en Falange Española fue desde la rama femenina del Sindicato Español Universitario (SEU) y que culminó con la desaparición de este: "Yo nunca he negado mi condición de antigua falangista hasta que José Antonio fue fusilado por sus ideas" (Alborg, 1993: 109). Como ella, otros intelectuales del momento, Dionisio Ridruejo, Gonzalo Torrente Ballester o Pedro Laín Entralgo, sintieron el mismo desengaño. Este sentimiento de desazón ideológica fue sentido

editorial Renacimiento publicó una edición en la que se han agrupado los tres tomos en un solo volumen titulado Pequeña historia de ayer, como era el deseo de la autora y que no pudo ver cumplido en vida. Las citas relativas a las memorias serán extraídas de esta edición de 2020.

${ }^{3}$ Falange Española arranca con el manifiesto que Primo de Rivera pronunció en el Teatro de la Comedia de Madrid el 29 de octubre de 1933. El movimiento se forjó principalmente en la Universidad, donde cobró fuerza a partir de la creación, casi a la par, del Sindicato Español Universitario (SEU), para hacerse con el monopolio de las facultades y controlar la opinión pública. Mercedes Formica reconoció que esta figura le fascinó, sobre todo, tras oír las siguientes palabras del líder en mencionado discurso fundacional: "No somos un partido de izquierda que, por destruirlo todo, destruye hasta lo bueno, ni de derechas que, por conservarlo todo, conserva hasta lo injusto". (2020: 179). A medados de febrero de 1934, se produce la fusión de Falange Española con las Juntas de Ofensiva Nacional Sindicalista, y surge así la nueva Falange Española de las JONS (Payne, 1965).

Futhark I5 (2020) 
verdaderamente por estos falangistas; tenían edad, bagaje cultural y formación intelectual para ello. No hay que esperar a la siguiente generación, la del 50, para que se hablara críticamente del franquismo. Formica, por ejemplo, supo bien las diferencias entre un falangismo, el nacido durante la II República, y el que evolucionó durante la guerra y después en el franquismo, a pesar de que su militancia juvenil tuviera lugar cuando la organización estaba en trance de consolidación de sus principios ${ }^{4}$. El haber recibido el influjo del krausismo como alumna universitaria en la República y haber disfrutado de una período dorado de la cultura española, donde brillaban la tolerancia, la diversidad y los aires de libertad, nunca se borraron de su memoria ${ }^{5}$. Sin embargo, puede que por el hecho de ser mujer y que, tradicionalmente, las producciones femeninas han sido menos consideradas que las masculinas para el canon literario, la figura de Mercedes Formica se haya visto envuelta en un injusto olvido, a diferencia de estos y otros compañeros, aun cuando su obra artística reúne los requisitos necesarios de calidad e interés como para haber traspasado el umbral del reconocimiento. En su caso, por tanto, además de su temprana afiliación falangista y ser englobada en la etiqueta de "los vencedores" de la guerra, aunque jamás se definió como tal, recae el peso de ser mujer creadora en aquellos años.

En este trabajo nos proponemos situar la carrera literaria de Formica dentro del panorama narrativo español de posguerra y darla a conocer a fin de que su obra sea más atendida por la crítica. La intención es que la autora sea tenida en cuenta como una de las voces más sugestivas y versátiles de su tiempo, y una de las mujeres de la Generación del 36, de la que, hasta la fecha, pese a discutirse su existencia, solo se cita al sector masculino que podría agruparse en ella, como si las mujeres no hubiesen participado de ese mundo cultural que surgió en los años treinta y se vio condicionado por el horror de una guerra que marcó sus vidas.

\section{El florecimiento de las mujeres escritoras durante la posguerra}

Para profundizar en la narrativa de posguerra, que es el género que cultiva Mercedes Formica, $y$, en general, en la literatura de la segunda mitad del siglo XX, siguen siendo necesarios los estudios de Nora (1962), Sobejano (1970), Soldevila Duarte (1980) y Martínez Cachero (1985), entre otros. Si antes hemos referido que Formica se reconocía miembro de la Generación del 36, fundamentalmente

\footnotetext{
${ }^{4}$ Sobre esta época, es decir, de la cultura fascista que surgió en España y su evolución, es recomendable el pionero estudio de Mainer (197I y 2013) y el ensayo de Gracia (2004).

${ }^{5}$ Para profundizar en la figura de Formica, pueden consultarse sus memorias, Pequeña historia de ayer, $y$ el prólogo de Soler Gallo, encargado de la edición, titulado "Olvidar no es sinónimo de traición" (2020a: 7-45). También es recomendable el trabajo de Soler Gallo "Feminismo, igualdad, franquismo: el desafío de Mercedes Formica en la búsqueda de una nueva identidad femenina" (2020b).

$\begin{array}{ll}\text { Futhark I5 (2020) } & \text { I } 72 \\ \text { II-24 }\end{array}$
}


por trayectoria vital y política, e igualmente por la temática de algunas de sus obras, sobre todo, las que presentan como eje la Guerra Civil y sus consecuencias, su carrera arranca a principios de la década de los cuarenta. Ciertamente, por estos años, se produce una eclosión de narradoras en España. En la actualidad, cuando se efectúa un estudio sobre la creación literaria en un determinado período de la historia de España, suele hablarse de obras de autores y autoras por igual, esto es, sin distinción de sexo, pero, cuando se estudia la posguerra, se tiende a segregar la producción de las mujeres de la de sus compañeros varones, porque, en efecto, se trató de un momento único para ellas, que modificó la tendencia preponderante y monopolizadora de estos en las letras. Así contamos con trabajos de referencia como los de Pérez (1983), de Asís (1991), Conde Peñalosa (2004) o Arias Careaga (2005). En concreto, De Asís documentó más de una decena de narradoras desde 1945 hasta 1960 (1991: 46): Carmen Laforet obtiene el Premio Nadal en 1944 con Nada, Mercedes Formica lanza Bodoque (1944-45), Rosa Chacel publica Memorias de Leticia Valle (1946), Eulalia Galvarriato, Cinco sombras (finalista del Nadal en 1946), Mercedes Ballesteros, Una mujer desconocida (1946). De esta autora pueden citarse otros títulos como Las mariposas cantan (1952) y Eclipse de Tierra (1954). Ana María Matute saca Los Abel (1948), Susana March, Nina (1949), Elena Quiroga, Viento del norte, Premio Nadal en 1950, Elena Soriano, Caza menor (I95I). Seguidamente a esta obra, la autora publicó la trilogía Mujer y hombre (1955), compuesta por La playa de los locos, Espejismos y Medea 55. En 1953 se da a conocer Dolores Medio, ganadora del Nadal por Nosotros los Rivero. En 1954 aparece la novelista Luisa Forenllad con Siempre en capilla, que obtiene el Nadal. Al año siguiente, se da a conocer Carmen Kurtz con Duermen bajo las aguas, Premio Ciudad de Barcelona. Ese mismo año es el de la publicación de El balneario de Carmen Martín Gaite, obra por la que recibe el Premio Café Gijón. 1955 es, del mismo modo, el lanzamiento de Mercedes Salisachs con Primera mañana, última mañana, finalista del Premio Planeta. En 1957, la publicista y crítica literaria Concha Castroviejo publica Los que se fueron y un año después Víspera del odio, novela que recibió el Premio Elisdenda de Moncada; ambas novelas se centran en la experiencia dolorosa de la Guerra Civil y del exilio.

Como se aprecia, durante la posguerra, que suele establecerse desde 193940 hasta 1960 (Conde Peñalosa, 2004), las mujeres escritoras ocuparon un amplio espacio de la narrativa española. Podemos apuntar algunos motivos. En primer lugar, la propia dictadura y el modelo de mujer que la Sección Femenina de Falange trataba de imponer en la sociedad hacían que esta quedase recluida en el hogar y que dispusiera de más tiempo para la lectura entre sus quehaceres domésticos y para escribir si poseía inquietudes artísticas ${ }^{6}$. En este sentido, en los años

${ }^{6}$ La Sección Femenina nace en 1934 de la mano de Pilar Primo de Rivera, hermana del líder falangista, para ocuparse del adoctrinamiento de las mujeres, en un principio, pertenecientes a Falange, pero, una

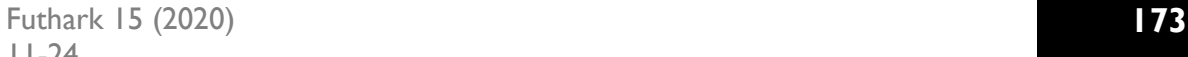


inmediatamente posteriores a la Guerra Civil, tuvo especial auge el cultivo y consumo de la denominada "novela rosa", ya que, por su esencia conservadora normalmente, las obras contaban historias de mujeres un tanto desvalidas y con futuros inciertos, que encontraban asidero y confortación en el amor de hombres mayores que ellas, estables desde el punto de vista emocional y bien posicionados económicamente-, era adecuada para perpetuar los tradicionales esquemas de género que defendía la retórica del Régimen y, además, servía de fabulosa vía de escape ante un panorama existencial oscuro. Son conocidos algunos nombres de autoras que destacaron en esta modalidad literaria, como el de Carmen de Icaza y su célebre novela Cristina Guzmán, profesora de idiomas, publicada inicialmente en 1936, en folletines en Blanco y Negro, pero reeditada después en múltiples ocasiones, que fue un auténtico éxito de ventas en plena posguerra -logró vender 250.000 ejemplares de 1940 a 1943, y fue traducida al italiano (Salani, Florencia; Mondadori, Milán), al francés (Le Temps, París), al portugués (Portugalia Editora, Lisboa), al alemán (Aare Verlag, Berna), al holandés (N. V. De Nederlandsche Boekhandel, Amberes; J. H. Gottmer, Haarlem), y al checo (Sfinx, Praga) $-^{7}$, Rosa María Aranda y su novela Boda en el Infierno (1942), Julia Maura, con Lola (194I), Eva y la vida (1943) y Como la tierra y el mar (1944?), o Concha Linares Becerra con títulos como Muchachas sin besos (1943) o El matrimonio es asunto de dos (1949). No resulta difícil imaginar que la novela rosa llegara a desentonar en un panorama literario en el que la otra corriente estética predominante era el tremendismo de La familia de Pascual Duarte de Camilo José Cela, radicalmente opuesta y asociada con los hombres y, en aquel tiempo, con la literatura de calidad. Luys Santa Marina indicó en La Estafeta Literaria, que "la literatura tremendista es novela rosa al revés, donde los escritores de este género se empeñan en acumular monstruosidades" (1956: 5). De la convivencia entre literatura culta y popular hay que hablar al estudiar las primeras décadas de la posguerra, aunque nosotros nos decantemos por hablar simplemente de literatura, de diferentes tendencias narrativas ${ }^{8}$.

vez que Franco se convierte en el vencedor de la contienda y en el nuevo Jefe del Estado, pasa a encargarse de la formación moral de todas las españolas. Seguidora del ideario tradicional de la mujer, cuyo fin puede resumirse en ser esposa y madre, la Sección Femenina tuvo vigencia hasta su extinción en 1977. Sobre la organización, pueden consultarse los trabajos de Gallego Méndez (1983), Sánchez López (1990) y Richmond (2004).

7 Carmen Martín Gaite denominó a Icaza "portavoz de un modelo literario" (2009: 85), en referencia a la novela rosa. Para López Jiménez, Martín Gaite es la única escritora española que ha mostrado cierta preocupación por descifrar las implicaciones sociales de este tipo de narraciones (I995: 3I). Estas obras le sirvieron a la autora salmantina, junto a las publicaciones femeninas del momento y los discursos, para la elaboración de su ensayo Usos amorosos de la postguerra española (1987). La novela Cristina Guzmán fue adaptada al cine, al teatro y a la televisión en distintos momentos. Sobre Icaza, véanse también los trabajos de Fragero Guerra (2017 y 2020).

${ }^{8}$ Caben citar algunos críticos que han llamado la atención sobre el imponente éxito que estas obras obtuvieron a partir de un estilo reconocible en muchos lugares del mundo. Véanse los estudios de Radway, 1984; López Jiménez, 1995; Labanji, 2002; Núñez Puente, 2008, y Soler Gallo, 2014 y 2017.

\begin{tabular}{l|l} 
Futhark I 5 (2020) & I74 \\
I I-24 &
\end{tabular}


Por otro lado, está la teoría basada en que las mujeres poseían una habilidad especial para narrar, idea sustentada en una concepción conservadora que asociaba esta supuesta destreza con la labor maternal, por ejemplo, con la acción de contar cuentos la madre a su descendencia para brindarle sosiego a la hora de dormir. Para la sociedad de entonces, la mujer narradora debía canalizar su arte en la problemática amorosa desde la visión de la mujer, es decir, como mujer debía explicar su psicología a la sociedad, especialmente, a la población femenina, que era la que más consumía estos temas, $y$, a su vez, revelar qué es lo que esperan encontrar de los hombres. La Estafeta Literaria trató este auge de la literatura femenina en una especie de reportaje titulado "Las mujeres y las novelas". Entre otras cuestiones, se argumentaba la idoneidad de vincular el género novelesco con la mujer. La escritora Julia Maura ofrecía su visión al respecto y decía que la novela era entretenimiento y la mujer "lo bonito de la vida" (1944: I). Ella debía ocuparse, esencialmente, del amor, y el hombre de "lo práctico, la dureza y dificultad de la investigación y de la ciencia" (1944: I).

Otro argumento sobre el incremento de las narradoras en el período de la posguerra es el que apunta a que las autoras buscaron en sus textos un medio de autodescubrimiento, de descargar su conciencia, de divulgar sus preocupaciones y pesares. Esto se fue agudizando a medida que la dictadura avanzaba y la sensación de asfixia era cada vez mayor, sobre todo, para aquellas autoras cercanas a los treinta años, que pudieron apreciar, durante la República, cómo se conseguían derechos y libertades para las mujeres, e incluso asistieron a la Universidad con la idea de labrarse un futuro profesional. Con tales objetivos nacieron muchas obras. También las novelas rosas evolucionaron. Los ambientes y paisajes se volvieron reales o verosímiles y las protagonistas no se limitaban a exteriorizar sus lamentos amorosos, sino que mostraban la soledad de una madre soltera o la frustración de una joven asfixiada por los condicionantes sociales que la condenan a la inactividad y al silencio. Ya no interesaban tanto las heroínas cenicientas que se encontraban con magnates millonarios que les solucionaban las vidas, sino que las protagonistas pasaron a luchar por abrirse paso ellas mismas a nivel profesional. Es decir, los argumentos se adecuaron a las necesidades de la vida real de la posguerra, en especial las de las mujeres, distintas a las de los hombres. Guadalupe Cabedo atisbó estas características en la obra de Laforet, Martín Gaite y Matute: "A través de los personajes ficticios de sus obras, hemos podido reconocer esas ansiedades que tenían bajo un régimen tan autoritario y limitado como era el del Generalísimo Franco" (Cabedo, 2013: 159).

Formica también habló del aumento de la narrativa femenina desde el final de la contienda en España en una conferencia que ofreció el 9 de mayo de 195I, como parte de los actos que se desarrollaban con motivo del I Congreso Femenino Hispanoamericano para celebrar el $\vee$ Centenario del nacimiento de la reina Isabel 
la Católica. La revista Ventanal, que fue el medio oficial elegido para divulgar el evento, en su séptimo número, correspondiente al 10 de mayo de aquel año, efectuó una reseña de aquella intervención de la cual podemos conocer que, en su opinión, la proliferación de tantas escritoras, con diversas orientaciones y calidad, no se había dado en número y dignidad literaria en las anteriores generaciones. El crecimiento de las vocaciones femeninas en el campo de las letras lo atribuía a la circunstancia de una mayor extensión de los medios culturales y al interés incrementado en la mujer por elevar su formación intelectual.

\section{I. La realidad, el compromiso: el itinerario narrativo de Mercedes Formica}

El nombre de la autora comienza a sonar con fuerza en el mundo literario a partir de 1950, casi al mismo tiempo en el que se inicia su actividad como abogada en Madrid, tras haber obtenido la licenciatura en Derecho un año antes en la Universidad Central ${ }^{9}$. Es entonces cuando queda finalista de certámenes literarios de renombre, como el Nadal o el Ciudad de Barcelona. Sin embargo, publicó seis títulos durante la década de los cuarenta, de los cuales no llegó a sentirse satisfecha con cuatro de ellos: Luisa Terry de la Vega (1942), Vuelve a mí (1943), „Peligro de amor! (1944) y Mi mujer eres tú (1946). Las tres últimas salieron al mercado con el pseudónimo de Elena Puerto y seguían el patrón de la novela rosa. Pese a ello, son obras dignas de análisis, pues revelan parte del pensamiento de la autora, muy avanzado para la época en lo que al papel de las mujeres en la sociedad se refiere. En tales obras las protagonistas transgreden el ideal de mujer tradicional defendido por la Sección Femenina. Trabajan fuera de casa, fuman (símbolo de insolencia y modernidad) y huyen de cualquier atisbo de matrimonio por conveniencia. Tanto en Vuelve a mí (Afrodisio Aguado), como en Mi mujer eres tú (autoedición) se realiza una feroz crítica a las clases pudientes de la época por considerar el dinero la principal fuente de felicidad y el bien fundamental que debía poseer toda familia, más allá del propio amor. Por consiguiente, se invierte el prototipo de mujer

\footnotetext{
${ }^{9}$ La carrera la inició, no obstante, en la Facultad de Derecho de Sevilla durante la República (curso 1931-32; este año alternó los estudios de Derecho con los de Filosofía y Letras). Pese al brillante expediente académico y la admiración que despertó entre sus profesores -"Mujeres de su talante es lo que necesita la República", le manifestó en una ocasión Manuel Martínez Pedroso, catedrático de Derecho Político (2020: 126)-, a causa del divorcio de sus padres en 1933, se vio obligada a trasladarse a Madrid (entonces estaba vigente el "depósito de la mujer casada" y se acordó la residencia de la parte vencida por la ley en esta ciudad), donde continuó sus estudios en el conocido "caserón de San Bernardo" y entró en contacto con la ideología falangista al poco de instituirse el movimiento. El estallido de la Guerra Civil, que la sorprendió en Málaga, provocó la interrupción de sus estudios, que no serían retomados hasta mediados de la década de los cuarenta, primero en la Universidad de Barcelona y, luego, en Madrid. Formica había contraído matrimonio el 20 de diciembre de $1937 \mathrm{con}$ Eduardo Llosent y Marañón, perteneciente al círculo intelectual sevillano de los años treinta, impulsor de muchos de los poetas del 27 y fundador, entre otras, de la revista Mediodía, donde participaron muchos de estos autores. El matrimonio duró hasta que el Tribunal Eclesiástico lo declaró nulo en 1960.

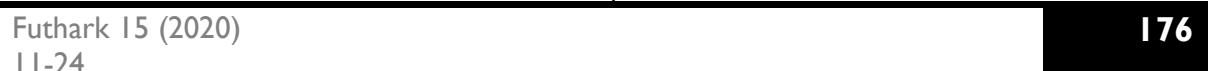


caritativa y dueña del hogar para presentar a una mujer valiente y capaz de realizarse y valerse por sí misma. En Peligro de amor, divulgada en folletines en la revista Medina de la Sección Femenina ${ }^{10}$ (entre el 12 de marzo y el 27 de septiembre de 1944), la protagonista es una estudiante de Derecho, como lo era la autora en el momento de la publicación. Las obras seguirían una especie de modernidad moderada para alejarse de la tonalidad rosácea que las catalogaban directamente como productos de dudosa calidad. Sobre el primer título, la insatisfacción venía condicionada por estar dedicada a una figura destacada de la Sección Femenina, Luisa Terry de la Vega, fallecida durante el bombardeo de Seseña, el 23 de septiembre de 1937, mientras desempeñaba labores en el Auxilio Social, pero no por la figura en sí, puesto que era amiga de la infancia, sino porque, conforme pasaba el tiempo e iban perdiéndose los referentes y diluyéndose los aires mesiánicos gerracivilistas, la obra perdía cualquier sentido. El relato hacía especial hincapié en el acto de generosidad que tuvo al dejar sus bienes y su pequeña fortuna a las obras sociales de la Sección Femenina antes de morir. La novela salió también por entregas en la revista Medina, entre el 3 de mayo y el 30 de agosto de 1942.

Las otras dos obras sí son significativas: Bodoque (1944-45), novela corta divulgada en la revista Escorial en dos números (50, diciembre de 1944, y $5 \mathrm{I}$, enero de 1945) -de los pocos casos narrativos de la publicación y de autoría femenina-, y La casa de los techos pintados (1946?), igualmente novela corta, de la que no se tenía constancia y que resulta fundamental para comprender, no solo el conjunto de su literatura, sino también su compromiso con los más indefensos, en aquel tiempo, las mujeres y los niños, que la motivó, una vez que finalizó la carrera de Derecho, a iniciar una campaña para transformar una serie de leyes que menoscababan su dignidad".

De una parte, en Bodoque la autora critica el sistema legislativo vigente en casos de desavenencias matrimoniales, suavizado -estratégicamente- al colocar como protagonista a un niño de unos ocho años. La novela centra su argumento en la infancia de este pequeño, que en realidad se trata de su propio hermano José,

\footnotetext{
${ }^{10}$ La revista Medina, en su tiempo, pretendía ser lo que Escorial para el público femenino, un espacio artístico cultural que diese cabida a autores de cualquier signo político. El primer número sale a la luz el 20 de mayo de 1941 y llega hasta diciembre de 1945. Mercedes Formica dirigió esta publicación unos ocho meses: desde el número correspondiente al 3 de agosto de 194I (número 20) hasta el número con fecha de 12 de abril de 1942 (número 56). Sin percibir ninguna compensación económica, dirigió una treintena de números y su modo de proceder mejoró el formato y los contenidos, pues incluyó más literatura y menos propaganda (a veces nada, excepto un resumen de las tareas de la Sección Femenina, que, por obligación, debían contener los números), y se ocupó de darles espacio a autores que querían iniciarse en la escritura, como Camilo José Cela, que publicó folletines, y a varias mujeres, como Mercedes Ballesteros o Elena Soriano.

"Recientemente, se han localizado otras obras desconocidas de la autora, que, junto a esta, están siendo estudiadas para su próxima divulgación.

$\begin{array}{ll}\text { Futhark I } 5(2020) & 177 \\ \text { | | -24 } & \end{array}$
}


apodado en la novela "Bodoque". La infancia trágica que se nos relata es consecuencia directa de la separación matrimonial de los padres. El pequeño es obligado a permanecer con su padre y la amante de éste -caracterizada de manera cruel- y a quedar aislado de su madre y de sus hermanas, según determinó la justicia. Bodoque tiene mucho de autobiografía, pues este episodio sucede calcado tras el divorcio de sus padres en 1933. Formica, por tanto, recrea el acontecimiento en la ficción, incluso ofreciendo el mismo nombre de su hermano, quien, como el personaje, crece bajo las nefastas consecuencias de una injusta ley de divorcio, que otorga todo el favor al hombre $y$ todas las penurias a la mujer. El hecho de que rememore una experiencia vital no debe restarle trascendencia al mensaje de la obra, puesto que, al ser publicada durante el régimen de Franco, está advirtiendo de que las leyes, antes (durante la República) y en su tiempo (la dictadura), poseen las mismas carencias. Es cierto que durante el franquismo no era posible el divorcio, pero sí la separación, y el Código Civil, en cuestiones relativas al Derecho privado, había permanecido sin mucho movimiento desde su promulgación en $1889^{12}$. Pese a haber sido publicada, Formica presentó la obra en 1950 al certamen "Arte y hogar" para novelas cortas, y obtuvo el segundo premio.

De otra parte, La casa de los techos pintados trata más directamente la violencia en la convivencia matrimonial y cómo la sociedad, que elude afrontar esta dramática situación, propicia que los hijos que la padecen como testigos directos, e igualmente víctimas, crezcan traumatizados, abúlicos, desesperanzados, hasta llegar a comprender que la única posibilidad que les queda es rebelarse contra un sino funesto para procurar enderezar sus trayectorias personales al margen de lo vivido. Como sucedía en Bodoque, el escenario elegido, la casa, personajes y vivencias forman parte de la vida real de la autora.

Con todo, fue en la década de los cincuenta cuando su carrera adquiere mayor presencia, como indicamos. Mercedes Formica habló de su técnica narrativa en una conferencia pronunciada en el Ateneo de Madrid en 1950, que luego se publicó con el título "Reflexiones sobre la novela" en Cuadernos de Literatura. En ella hablaba de su interés por el mundo que la rodeaba: "[Este interés] me acercó

12 El artículo 44 de la Ley de Divorcio de 2 de marzo de 1932 mantuvo el 1.880 (y siguientes) de la Ley de Enjuiciamiento Civil, que regulaba el "depósito de la mujer casada" en caso de ruptura matrimonial por considerarse el domicilio conyugal "casa del marido", por lo que la mujer era "depositada" en la casa de los padres, si los tenía, en la de unos amigos, si los tuviera, bajo la vigilancia de un "depositario" escogido por el marido, aunque fuese el cónyuge culpable o un maltratador, o en un convento, con la pérdida de la guarda custodia de los hijos durante el tiempo que duraba el proceso, que, con apelaciones, podía alargarse de seis a nueve años. Además, la pensión alimenticia era siempre incierta. La tímida penalidad del artículo 34 -una alternativa entre multa y prisión- nunca se aplicó, razón que explicaba la falta de jurisprudencia sobre la materia. Señalamos únicamente aquellas cuestiones relacionadas con Bodoque. La novela ha sido reeditada en 2018 por la editorial Renacimiento ("Espuela de Plata”, en el volumen A instancia de parte y dos obras más, a cargo de Miguel Soler Gallo, autor también del estudio introductorio. 
siempre a los hechos, a las personas y a las cosas con voluntad de retener su interés y narrarlo algún día". A la hora de convertir en materia literaria un suceso extraído de la realidad, la autora partía de una premisa: otorgar todo el protagonismo al ser y que el cúmulo de circunstancias que lo rodeara fuesen las que justificaran sus reacciones. Este modo de proceder recuerda al pensamiento orteguiano, a quien la autora confesaba seguir, como muchos autores de la Generación del 36. Es decir, el interés se transfiere de la trama a las figuras, de los actos a las personas, siempre creando una ilusión de autenticidad para que no se percibiese la novela como tal. Formica entendía que la trama poco importaba, pero ningún asunto, por anodino que pareciese o por espectacular y trepidante, también por lo folletinesco, lo rechazaba. La trama solo le servía de fondo. El ambiente estaba, en su visión, en un nivel superior, pero tampoco bastaba por sí solo, puesto que la médula estaba en los seres. En la conferencia reconocía que la novela de su época bebía de las ideas de Ortega y Gasset, pues estas coincidían con las producciones de maestros de la talla de Joyce y Faulkner: el triunfo de una técnica más depurada e intelectual, más medida, donde todo ha sido previsto ${ }^{13}$.

Monte de Sancha es la siguiente obra de la autora, la cual quedó finalista del Premio Ciudad de Barcelona y, por este motivo, fue publicada en la editorial Luis de Caralt, en la colección "Gigante"|4 . Se trata de una novela importante para comprender el espíritu de la Generación del 36, aquella que vio inmolada su juventud y sus ilusiones. Ambientada en la Guerra Civil, se recrean los hechos vividos por la autora en Málaga, zona republicana, que quedarán almacenados en sus recuerdos y se verán completados al llegar a Sevilla, zona nacional, en septiembre de 1936, y perciba la brutalidad del conflicto por ambos bandos, tal y como cuenta en el tomo de memorias Visto y vivido:

Mi único deseo era ir a Sevilla, contribuir a que la guerra se acabase y no se derramase más sangre. Llegué a zona nacional [...] Recién llegada del "otro lado" [República], creía ingenuamente, que en éste, en el "mío" [Falange], no se mataba [...] El hecho de saber que se mataba "en mi lado", me produjo intensa congoja (2020: 286-288).

La autora presencia en Málaga los primeros incendios y los saqueos de las viviendas de la zona adinerada de la ciudad. El relato transcurre por los elegantes barrios residenciales habitados, en su mayoría, por gentes de origen

\footnotetext{
13 Junto con Antonio Marichalar en Revista de Occidente, Formica se preocupó de introducir en España las señas literarias de ambos autores, a sabiendas de que podía ser tachada de esnobista. Pero, para ella, estos habían llevado a cabo una transformación en el panorama narrativo internacional semejante a la producida en el terreno plástico por Pablo Picasso.

${ }^{14} \mathrm{La}$ obra fue reeditada en 1999 en la editorial malagueña El Aguacero, con prólogo de Francisco Chica, e incluyó modificaciones de estilo hechas por la autora. En 2015, Renacimiento, "Espuela de Plata", llevó a cabo una edición facsímil con prólogo de Miguel Soler Gallo. De esta edición tomamos las citas expuestas en el texto.

\begin{tabular}{l|l} 
Futhark I $5(2020)$ & I79 \\
I |-24 &
\end{tabular}
}


centroeuropeo, instaladas en la ciudad a mediados del siglo XIX: el Limonar, los Paseos de Reding y Sancha, la Caleta, Bellavista. En contraste con estas zonas estaban los de la gente trabajadora del Perchel y de la Trinidad. La protagonista de la novela es Margarita Bradley, un personaje simbólico que encarna los destinos de toda la clase social a la que pertenece, y cuyo único vestigio de su esplendor económico son las hermosas casas en la que aún habitan los descendientes. De modo que el personaje protagonista se sitúa en el centro y las circunstancias que vive, propias de una guerra, perfilan su paso por el argumento, sin comprender el porqué del odio que despierta. La trama se complica al enamorarse de un muchacho del barrio de la Trinidad, Miguel, un escultor que pretende ignorar también la situación imperante. Cuando empiezan los primeros incidentes, los jóvenes dejan a un lado el amor, ya que la unión parece imposible:

Tú y yo -dice Miguel- pensábamos que, sin hacer un mal concreto a nadie bastaba para vivir en paz. Pero ahora he sabido que sentir la indiferencia hacia lo que te rodea, hacia lo que, queriéndolo o no, ha sido señalado como tuyo, es la mayor perversidad que puede cometer el ser una criatura humana (2015: 233).

Los crímenes se suceden incontrolablemente, Miguel mata al joven que Margarita esconde en su casa y ella muere víctima de una venganza personal de una joven enamorada de Miguel, Victoria, quien vivirá en la casa de su rival. Estamos ante una novela fuertemente politizada, donde las discusiones reflejan muy bien el ambiente beligerante de la época. Sin embargo, no se ensalza a ningún bando concreto, sino el laberinto de horror que produce el caos de cualquier guerra, pese a que las descripciones procedan en su mayoría de las actuaciones del lado republicano, que son los hechos que vive la autora en aquella Málaga y, por ende, su protagonista.

Poco después, en 1951, aparecen dos nuevas publicaciones: un cuento titulado La mano de la niña, publicado en el número 10 de la revista Clavileño ${ }^{15}$, y su siguiente novela $\mathrm{La}$ ciudad perdida, editada también en Luis de Caralt y dedicada como la anterior a la Guerra Civil, pero desde una perspectiva diferente: en este caso se trata de un narrador que recuerda los hechos vividos y no un narrador testigo como en la anterior novela. Mercedes Formica sitúa los hechos, esta vez, en

${ }^{15}$ En el consejo de redacción de la revista figuraban nombres como los de Dámaso Alonso, Valbuena Prat o Camilo José Cela. El cuento está dedicado al fallecimiento de su hermana Marita, la pequeña de la familia Formica-Corsi Hezode, en 1945, con apenas catorce años de edad, y puede intuirse la tristeza de la niña al no estar cerca de su padre y de su hermano después del divorcio. Además de los padres, la familia se completaba con cinco hermanas y un hermano: María Luisa, Mercedes, Elena, Margarita, José María y Marita. En 1927, falleció igualmente la hermana mayor. Esta obra ha sido reeditada en 2018 e incluida en el volumen $A$ instancia de parte y dos obras más (Renacimiento, "Espuela de Plata"). Se trata de uno de los pocos cuentos de la autora, que reconocía no sentirse cómoda en este género por su escasa capacidad de síntesis.

\begin{tabular}{l|l} 
Futhark I $5(2020)$ & 180 \\
| | - 24 &
\end{tabular}


la primera posguerra, cuando un excombatiente, Rafa, del bando republicano se infiltra en España para intentar imponer los ideales por los que luchó. Todos sus compañeros han muerto y él sabe que caerá pronto en manos de la policía. En el Retiro - la ciudad perdida es Madrid-, se encuentra a María, una joven viuda de un integrante del bando nacional, y decide abusar de ella llevándosela forzosamente a un descampado. Estando allí le vienen a la mente toda su vida pasada, su infancia, su adolescencia, sus estudios de medicina, su idealismo de izquierda, la decepción de los suyos durante la guerra, su huida a Francia. Todo en una confidencia sincera con María que provoca en la mujer un repentino sentimiento de amor, de protección y de miedo, un posible caso de síndrome de Estocolmo. La policía cerca finalmente a la pareja, $y$, antes de darles captura, se declaran su amor. La protagonista dispara contra Rafa a fin de salvar su alma y evitar que acabe él con su propia vida, o sea, suicidándose. María tendrá el resto de su vida para expiar su alma.

A través de toda la novela se perciben los efectos de la guerra como algo definitivamente conflictivo y sin ninguna justificación posible: "el fin más noble no justificará esta sangre". La novela la tituló, primeramente, En las calles de Madrid, y como tal llegó hasta las votaciones finales del Premio Nadal de 1950, que ganó ese año Elena Quiroga con Viento del norte. La ciudad perdida fue adaptada al cine con este título, en coproducción italiana de Nervión Films-Pico Films, en 1954. Asimismo, Luis Escobar hizo una versión teatral con el nombre de Un hombre y una mujer.

En medio de esta cada vez más frenética actividad literaria, Formica dirige dos nuevas publicaciones: en 1952, Feria, una versión española de la francesa Elle, y la segunda edición de La novela del sábado en 1953, con un elenco de colaboraciones que reunió a importantes figuras del momento y que sacó a flote semanalmente obras maestras de la novela corta. Abrió José María Pemán y le siguieron, entre otros muchos, Elena Quiroga, Cela, Laforet, Delibes, Matute, José Luis Acquaroni, Torrente Ballester, etc. Por otro lado, finaliza su carrera en Derecho, en 1949, y abre su propio despacho en su domicilio del Paseo de Recoletos de Madrid, arriba del Café Gijón, especializándose en casos de violencia contra la mujer. Igualmente, se inicia como articulista en el periódico $A B C$, de la que llegó de la mano de Torcuato Luca de Tena. Desde las páginas de este diario, uno de los de mayor tirada de la época, llevó a cabo una campaña de resonancias nacionales e internacionales a favor de los derechos de la mujer española ${ }^{16}$.

${ }^{16}$ El nombre de Mercedes Formica apareció en las portadas de las principales revistas y periódicos del país y del extranjero, los cuales recogían la labor realizada por la autora para lograr la ansiada igualdad legislativa de la mujer en el Código Civil o, al menos, acercar a la mujer en derechos respecto al hombre. El origen de tanto revuelo fue un artículo suyo publicado en $A B C$, el 7 de noviembre de 1953 , titulado "El domicilio conyugal", en el que denunciaba la terrible situación de la mujer casada española víctima de violencia machista, ya que que se veía impedida para poder separarse porque lo perdía todo: casa, hijos, bienes. Revistas como la estadounidense Time o el periódico The New York Times; diarios

\begin{tabular}{l|l|l|l|l|l|} 
Futhark I5 (2020) & I8 I \\
I|-24
\end{tabular}


En 1953, sale a la luz una novela corta titulada El secreto, en el número 33 de La novela del sábado. El tema central era atrevido para la época: los errores cometidos por la justicia que condena a seres inocentes sin tener la certeza absoluta. La novela se desarrolla en Niterói, ciudad del Estado de Río de Janeiro y el protagonista es Adalberto Cajatty, un militar, educado por sus abuelos, que, tras morir su madre, se hace cargo de la educación de sus hermanas, Aleluya y Eleonora. Cierto día, estando las hermanas internas, decide sacarlas del colegio y pasar unos días de vacaciones con ellas. Las embarca rumbo a la casa de unos familiares, a los que les había alquilado dos habitaciones. Adalberto saldría después hacia ese destino porque debía despedirse antes de su novia. Cuando llega, de noche, a la casa, las hermanas y los familiares duermen, y se oye un disparo que procede de la habitación en la que duermen sus hermanas. Al llegar, se encuentra a Eleonora muerta en el suelo, junto a su pistola.

El hecho se complica en el momento en el que un tío de Adalberto planea tenderle una trampa para que sea acusado del asesinato de su hermana y no su hijo, a quien se le señala como el verdadero responsable. Por ello, convence a su otra hermana, Aleluya, y al propio padre para que lo acusen. Adalberto es detenido y sentenciado a la horca, de la que acaba librándose por su edad. En su lugar, pasará el resto de sus días en la cárcel. Finalmente, su tío cae enfermo y, antes de morir, confiesa la verdad y pide la excarcelación de Adalberto. Al recobrar la libertad, cae muerto de un infarto.

Si Formica no hubiese trasladado los hechos a Brasil, seguramente habría tenido problemas con la censura (más cuando el argumento estaba inspirado en un caso real ocurrido en Madrid). En la obra, el folletín se ve superado por el deambular de un hombre frente a sus circunstancias; la trama, es secundaria. Como pasa con muchos autores y autoras que escribieron bajo los condicionantes del nacionalcatolicismo, estas deberían ser analizadas, en la actualidad, sin perder de vista el contexto histórico en el que fueron publicadas. Sobre todo, analizando los finales de las obras, que suelen ser abruptos y conservadores, acordes con la moral. Así lo reconocía Formica a la crítica Concha Alborg: "Tú piensa que yo estaba escribiendo en un medio hostil a lo que yo pensaba" (1993: III). Y en el tercer tomo de sus memorias, Espejo roto. $Y$ espejuelos, sobre el final de La ciudad perdida, que resultaba poco verosímil, decía: "Los escritores de aquellos días nos sometíamos a determinadas exigencias o no publicábamos” (2020: 500).

suizos, alemanes, italianos, Die Weltwoche (Zurich), Kölner Stadt-Anzeiger, Oggi, B. T., comentaron la noticia. La repercusión también llegó a los países latinoamericanos; tal es el caso de La Prensa (Buenos Aires), Diario Carioca (Brasil), El Colombiano (Colombia), Visión (México), Mañana (Cuba) o el semanario CNT, entre otros. Estos datos aparecen recogidos en sus memorias, concretamente, en el tomo Espejo roto. $Y$ espejuelos.

Futhark I 5 (2020) 
Dos años más tarde, hace lo propio $A$ instancia de parte, cuyo título ya indica un procedimiento judicial, en este caso referido el adulterio, penado únicamente en la mujer, por lo que era un delito privado y se perseguía no por el Estado, sino a instancia de la parte ofendida, es decir, el marido. El hilo conductor de la novela es el drama de un esposo engañado, Chano Maldonado, que sufre las consecuencias del machismo prevalente en la sociedad, debido a que se niega a seguir el código ancestral que le obliga a rechazar a su esposa, Esperanza, y vengarse de su infidelidad. En segundo lugar está Julián, perteneciente a la misma casta que Chano e impulsor del rechazo social de éste. Julián emigra a Filipinas donde se casa con una mujer nativa y de quien tiene un hijo, al regresar a España siente rechazo racial hacia su mujer y trama una situación que ante los ojos de las leyes culpe a su mujer de infidelidad y acabe acusada de adulterio. La mujer de Julián, Aurelia, es la que transmite el mensaje que la autora pretende mostrar: el triunfo del más fuerte (el hombre) en las leyes.

Si en la legislación vigente entonces, el marido matara o hiriera a la mujer adúltera, o a su amante, quedaría exento de culpa; por el contrario, para la condena de la mujer era suficiente la tan simple prueba de una apariencia. $Y$ en la novela basta que Aurelia, que acude a la casa de Chano, inducida por su marido, sea vista allí, en una habitación perfectamente diseñada (con aspecto de haberse producido un encuentro amoroso), para que se resuelva judicialmente su confinamiento en una Casa de arrepentidas, con privación incluso de poder ver a su hijo. La novela es galardonada con el premio Cid (de la cadena SER) por un jurado integrado por reconocidos intelectuales de aquel momento: Dámaso Alonso, Dionisio Ridruejo, Melchor Fernández Almagro, José Luis Carreño y Carmen Laforet, entre otros. Formica presentó la obra bajo el pseudónimo de Demetrio Ron, una identidad masculina con la que, probablemente, evitaría el recelo de un jurado -constituido en su mayoría por hombres- a la hora de tener que valorar un asunto de tipo jurídico, es decir, "serio", en la pluma de una mujer; o para impedir que la novela fuese desatendida al coincidir en el tiempo con su campaña por los derechos de las mujeres ${ }^{17}$.

\footnotetext{
${ }^{17}$ La obra fue reeditada en 1991 por María Elena Bravo para Castalia ("Biblioteca de Escritoras"), con correcciones de estilo hechas por Formica. Del mismo modo, es la obra central, facsímil de la edición de 1955, del volumen $A$ instancia de parte y dos obras más. De este tomo, publicado en 2018 por Renacimiento ("Espuela de Plata"), además del apartado dedicado a la obra en el estudio introductorio titulado "Un aroma corrompido" y de contener Bodoque y el cuento "La mano de la niña", es de interés el apéndice documental en el que se recogen textos de la autora relacionados con la materia, como la recensión que hizo en 1950 de El segundo sexo de Simone de Beauvoir, al poco de publicarse en Francia y ser en España un libro de difícil circulación al ser prohibido por el Vaticano. Es decir, a Formica se le debe la introducción de este trascendental ensayo, cuyas tesis colisionaban con los dogmas de la Sección Femenina $y$, por tanto, del Régimen, en la España nacionalcatólica. Una prueba evidente del distanciamiento de Formica de aquella militancia juvenil en Falange. 
Hasta la década de los sesenta, su actividad se había centrado en la enardecida defensa de los más débiles en situaciones de opresión, fundamentalmente, la mujer y los niños, cuyo tesón y firmeza desembocaron en la reforma de sesenta y seis de artículos del Código Civil en 1958, conocida con el nombre de "la Reformica", como la bautizó, por afecto, el también abogado Antonio Garrigues. Significó la primera reforma de este cuerpo legal para incluir derechos a las mujeres desde su promulgación en 1889 , y afectó al Código de Comercio, Ley de Enjuiciamiento Civil y Código Penal ${ }^{18}$.

Tras este importante hito a favor de la igualdad entre los sexos, Mercedes Formica abandona el ejercicio de la abogacía ${ }^{19}$, pero continúa sus colaboraciones en el periódico $A B C$ hasta casi el final de sus días. Dispuso de una sección fija, " $A B C$ de la Mujer", desde 1967 hasta 197I, con una colaboración cada domingo, en la que se tratan otras cuestiones sociales como la mujer soltera con capacidad para adoptar, la mujer universitaria o la defensa también de las personas mayores.

Gracias a su interés por conocer la situación social y jurídica de las mujeres españolas a lo largo de la historia, emprende una importante labor de investigación histórica, las cuales se ven recompensadas con el resultado de dos biografías de gran interés tanto por su rigor histórico como por su estilo literario y en las que nunca abandonó su perspectiva de mujer para tratar a la mujer. En 1973, publica La hija de don Juan de Austria, con prólogo de Julio Caro Baroja, en Ediciones de la Revista de Occidente, que supone un interesante estudio por el que recibe el prestigioso Premio Fastenrath de la Real Academia Española. En 1979, editorial Caro Raggio, se completa con la biografía de María de Mendoza (Solución a un enigma amoroso), amante de don Juan de Austria y madre de Ana de Jesús.

\footnotetext{
18 Entre otros cambios, se suprimió el "depósito de la mujer casada", como había denunciado insistentemente la autora en sus artículos de prensa y en Bodoque sobre todo, y, como consecuencia, la "casa del marido" pasó a denominarse el domicilio de la familia o domicilio familiar, por lo que la mujer, si el juez lo consideraba, podía quedarse en la casa en caso de separación; la mujer que contraía segundas nupcias no perdía los derechos sobre los hijos del primer matrimonio, si los tenía, y los bienes que tuviera antes de contraer matrimonio seguirían siendo suyos tras la separación, sin que pasasen a manos del marido. Como había reclamado en su novela $A$ instancia de parte, el adulterio fue considerado, en el artículo 105 del Código Civil, "motivo de separación si lo cometía cualquiera de los dos cónyuges", y, a nivel penal, el marido que mataba a la mujer "adúltera" era condenado por homicidio con "poderosos atenuantes de obcecación y arrebato". No obstante, seguía siendo delito. La despenalización del adulterio no llegó a España hasta 1978. Del mismo modo, la reforma del Código Civil de 1958 sirvió para que las mujeres fueran conscientes de la escalofriante situación en la que se encontraban en las leyes, materia esta que, hasta la fecha, no habían considerado de su incumbencia. Para más información, véanse las memorias de Formica (2020).

19 En 1962, dos años después de la nulidad de su matrimonio con Llosent (véase nota 9), contrajo segundas nupcias con el ingeniero industrial José María González de Careaga, a quien no le gustaba especialmente que su esposa tuviera tantas ocupaciones profesionales. 
Junto a su labor investigadora, inicia la redacción y publicación de sus tres tomos de memorias, que ya hemos referido. En 1987, publica una autobiografía novelada con el título de La infancia, la cual bien podría ocupar el primero de los tomos de sus memorias, aunque parte de las vivencias se recogen en Visto y vivido ${ }^{20}$. También es autora de una seria de ensayos que, salvo alguna excepción, como el citado "Reflexiones sobre la novela", giran en torno al feminismo o a analizan personajes históricos femeninos. Así tenemos: "El año internacional de la mujer y la situación jurídica de la mujer española", con motivo de esta celebración fijada por la ONU en 1975; "Falsas y verdades formas del feminismo" (1975); "La infanta Catalina Micaela en la Corte Alegre de Turín" (1976); "La mujer" (I985) ○ "El misterio de doña Clara-Eugenia de Austria" (1997), personaje relacionado con el de Ana de Austria.

Su última novela publicada es Collar de ámbar (1989), en donde profundizaba en otro de los temas que más le interesaron a lo largo de su vida, la cultura hebrea en España. Este asunto llegó a convertirse en una verdadera obsesión para la autora. Como indica Pablo Castellano en el prólogo de la novela, publicada en la editorial Caro Raggio, los sefardíes que vivieron en España, son para Formica "los fantasmas de una estirpe obligada a vagar, desarraigada, a quien no solo se niega su identidad, su corporeidad, su cultura y su historia, de quienes se quiere borrar hasta la memoria", una vez que se produjo su expulsión en 1492. Lo que hace la autora en Collar de ámbar es trazar las huellas perdidas de este pueblo con el que ella se sentía tan identificada. La obra, aunque publicada en 1989, estaba escrita, al menos una primera versión, en 1963.

En abril de 1997, la Residencia de Estudiantes de Madrid rinde homenaje a Mercedes Formica, en el único acto público efectuado en la democracia para reconocer la labor profesional e intelectual de la autora. Falleció el 22 de abril de 2002 en Málaga.

\section{Conclusiones}

Es evidente que vivir una guerra con plena conciencia debe transformar la concepción del mundo de las personas. Aunque el asunto de la contienda española se convirtió en un género literario concreto, del que aún se siguen publicando obras, hay que tener en cuenta que, en un principio, las surgidas durante e inmediatamente después de la contienda, contenían mucho de documental, de reportaje, en el que se relega el plano ficcional a un segundo plano por la preponderancia del elemento histórico. Baquero Goyanes decía que "pocos temas existen tan densos novelísticamente y hasta tan capaces de revelar la oriundez

${ }^{20}$ En esta obra rescata pasajes de la novela Luisa Terry de la Vega para enmarcar sus primeros años de vida en Cádiz, pero ya sin la aparición de esta.

Futhark I5 (2020) 
épica de un género literario" (1952: 12). No obstante, a medida que la década de los cuarenta avanzaba, el relato impera y se centra en describir las consecuencias, el silencio y las reacciones de los individuos ante unas circunstancias adversas, como hizo Mercedes Formica con Monte de Sancha y La ciudad perdida, pero también las otras de los años de la posguerra, las que revelan injusticias, por ejemplo, donde expresa su compromiso con quienes mostraban más debilidad ante el predominio de la fuerza, pero también las que presentan como tema el amor, pues lo que de él puedan contener de fantasía, no es más que una reacción de búsqueda de evasión ante un horizonte con pocas expectativas de libertad. En general, las escritoras quisieron contar sus vivencias, de viva voz o a través de sus personajes, y no que fuesen contadas por ellas, e igualmente dar cobertura a aquellas personas que, para el discurso oficial, no tenían cabida o no estaban bien representadas.

A través de la trayectoria literaria de Mercedes Formica queremos llamar la atención sobre la generación del 36 , y en concreto, sobre las mujeres que la integrarían, aún por estudiar en profundidad. Cierto es que en la posguerra coincide este grupo con el del 50 o del Mediosiglo. Formica habló así de esta última en sus memorias:

Ignoraban, conscientes, a los precursores hispanos, a Ramón María del ValleInclán, Miguel Mihura, Jardiel Poncela. Nunca padecieron los errores de la República, ni el trauma de la guerra, y consideraban a Rusia el paraíso de todas las utopías cerrando los ojos a las "purgas" estalinistas denunciadas en El Cero y el Infinito, por un comunista tan libre de sospechas como Arthur Koestler. [...] Estos jóvenes ignoraron los problemas de la infancia, los de la mujer, aquellos que afectaban a las universitarias. Hubiera resultado útil protestar a gritos, contra la exigencia de "ser varón" a las licenciadas, contra el humillante depósito de la casada tratada como una cosa, de su muerte en caso de adulterio sin más condena para el asesino que tres meses de destierro. Nunca les interesaron las pensiones alimenticias en favor de los hijos de parejas separadas, siempre insuficientes y con frecuencia impagadas. La generación de los cincuenta calló (2020: 508-509).

Como vemos, no se refería al estilo o a la técnica narrativa de esta generación, sino a cuestiones vitales, a experiencias que, por edad, una vivió o tuvo pleno conocimiento de ello, y la otra tenía que profundizar en determinados aspectos por medio de otras personas o a través de los libros. En este sentido, las narradoras del 36 abordarían líneas argumentales en las obras que son esenciales para conocer cómo vivían y se desenvolvían las mujeres españolas de entonces. Los títulos de los tomos de memorias que Mercedes Formica publicó resultan reveladores en ese interés de querer contar aquello que se protagonizó: Visto y vivido, que relata los años de la II República y los primeros episodios de la guerra; Escucho el silencio, que recoge el resto de la contienda y la posguerra hasta 1947, y, 
por último, Espejo roto. $Y$ espejuelos, en el que se condensa buena parte de sus vivencias durante la década de los cincuenta, $y$, como el propio título indica, se antoja significativo para comprender su evolución ideológica. Como ella, nacida en 1913, las producciones de autoras nacidas entre 1906 y 1914, según señala Ricardo Gullón para que exista coetaneidad entre los miembros (1965: I y 24), aunque se podría extender hasta 1920 o 1921, Julia Maura (1910), Concha Linares Becerra (1910), Dolores Medio (191I), Carmen Kurtz (1911), Susana March (1915), Mercedes Salisachs (1916), Mercedes Ballesteros (1913), Concha Castroviejo (1913), Elena Soriano (1917), Rosa María Aranda (1920), Elena Quiroga (1921), entre otras, merecen atención, ya que, en muchos casos, se adelantaron con un tipo de novela testimonial denunciando y reflejando una existencia dramática que continuará con otros matices en el realismo social de la generación siguiente. El sentimentalismo o esa preocupación por el asunto amoroso, que se podría desprender de la novela rosa, dio paso al tratamiento de temas más profundos como la soledad, el abandono, la injusticia, la incomprensión, la enfermedad, el engaño y la enajenación, asuntos que bien podrían identificar a la narrativa femenina del 36, como consecuencia de esa consideración que el franquismo otorgó a las mujeres de ciudadanos de segunda categoría, después de haber vivido estas, en su primera juventud, un mundo de oportunidades durante la República, que ni las autoras de ideología conservadora pudieron obviar la sensación de frustración que sintieron.

\section{Bibliografía}

ALBORG, C. (1993). Cinco figuras en torno a la novela de posguerra: Galvarriato, Soriano, Formica, Boixadós y Aldecoa. Madrid: Libertarias.

ANÓNIMO (I 944, 5 marzo). Las mujeres y las novelas. La Estafeta Literaria I, I.

ANÓNIMO (1956, 6 octubre). Luys Santa Marina enfoca el panorama literario. La Estafeta Literaria, 64, 5.

ANÓNIMO. (I95I, 10 mayo). Conferencia sobre narrativa femenina. Ventanal, 7, 5.

ARIAS CAREAGA, R. (2005). Escritoras españolas (1939-1975): poesía, novela y teatro. Madrid: Ediciones del Laberinto.

Asís, M. ${ }^{a}$ D. de (199I). La novela escrita por mujeres. Veintiuno. Revista de pensamiento político, 10, 46-64.

BAQUERO GoYANES, M. (I 952). La guerra española en nuestra novela. Ateneo, 3, I, I2-I3.

CABEDO, G. M. (20/3). La madre ausente en la novela española de posguerra española: pérdida y liberación (Estudio de tres obras de Carmen Laforet, Carmen Martín Gaite y Ana María Matute). EE.UU: Palibrio.

Conde PeÑalosa, R. (2004). La novela femenina de posguerra (1940 - 1960). Madrid: Pliegos. 
Ferrán, J. y Testa, D. P. (eds.) (1973). Spanish Writers of 1936: Crisis and Commitment in the Poetry of the Thirties and Forties. Londres: Tamesis.

FORMICA, M. (1950). Reflexiones sobre la novela. Cuadernos de Literatura, 7, 249 266.

(20I5). Monte de Sancha, pról. de Miguel Soler Gallo. Sevilla: Renacimiento (Espuela de Plata).

(20I8). A instancia de parte y dos obras más, ed. y estudio introductorio de Miguel Soler Gallo. Sevilla: Renacimiento.

. (2020). Pequeña historia de ayer (Memorias), ed. y pról. de Miguel Soler Gallo. Sevilla: Renacimiento.

Fragero GuerRA, C. (20I7). Del azul al rosa: la narrativa de Carmen de Icaza (1936-1960). Madrid: Sial Pigmalion.

Fragero Guerra, C. (2020). Carmen de lcaza: imagen de identidad femenina durante el primer franquismo (1936-1949). En: Fernéndez Ulloa, T. y Soler Gallo, M. (eds.), Aproximaciones a la configuración de la identidad en la cultura y sociedad hispanas e italianas contemporáneas. Madrid: Liceus, 6I87.

Gallego MÉNDEZ, M. ${ }^{\text {a }}$ T. (1983). Mujer, falange y franquismo. Madrid: Taurus.

GARCÍA DE LA CONCHA, V. (1987). La poesía española de 1935 a 1975. Madrid: Cátedra.

GULLÓN, R. (1965, julio). La generación española del 36. Ínsula, 224-225, Iy 24.

LABANYI, J. (2002). Resemanticizing Feminine Surrender: cross-gender identification in the writings of Spanish female Fascist activists. In: Ferrán, O. and Glenn, K. M. (eds), Women's Narrative and Film in Twentieth-Century Spain: A World of Difference(s). Nueva York y Londres: Routledge.

LÓPEZ JIMÉNEZ, F. (1995). Mito y discurso en la novela femenina de posguerra en España. Madrid: Pliegos.

MAINER, J. C. (I97I): Falange y Literatura. Labor: Barcelona (20I3. Barcelona: RBA)

MARTÍN GAITE, C. (2009). El cuarto de atrás. Madrid: Siruela.

MARTínez CACHERO, J. M. ${ }^{a}$ (1985). La novela española entre 1936 y 1980. Historia de una aventura. Madrid: Castalia.

NORA, E. G. de (1962). La novela española contemporánea, tomo II. Madrid, Gredos.

NúÑEZ PUENTE, S. (2008). Reescribir la femineidad: la mujer y el discurso cultural en la España Contemporánea. Madrid: Pliegos.

PAYNE, S. G. (1965). Falange. Historia del fascismo español. París: Ruedo lbérico. . (1997). Franco y José Antonio. El extraño caso del fascismo español. Barcelona: Planeta.

PÉREZ, J. W. (ed.) (1983). Novelistas femeninas de la posguerra española. Madrid: Porrúa Turanzas. 
RADWAY, J. (1984). Reading the Romance: Women, Patriarchy, and Popular Literature. Carolina del Norte: The University of North Carolina Press.

RichMOND, K. (2004). Las mujeres en el fascismo español. La Sección Femenina de la Falange (1935-1959). Madrid: Alianza.

SÁNCHEZ LÓPEZ, R. (1990). Mujer española, una sombra de destino universal: trayectoria histórica de la Sección Femenina. Murcia: Universidad de Murcia.

SERIS, H. (1945). The Spanish Generation of 1936. Books Abroad, 19, 336-340.

SOBEjANO, G. (1970). Novela española de nuestro tiempo (en busca del pueblo perdido). Madrid: Prensa Española.

SOLDEVILA DURANTE, I. (1980). La novela desde 1936. Madrid: Alhambra.

SOleR GALLO, M. (20l4). El Bien y el Mal: Modelos de conducta femeninos en la novela rosa de los 40. En: Greco, B. y Pache Carballo, L. (eds.), Variaciones de lo metarreal en la España de los siglos XX y XX. Madrid: Biblioteca Nueva, $83-93$

(2017). El juego amoroso en la novela rosa española femenina de los años cuarenta. En: Santos Alpalhão, M., Clamote Carrero, C. y Barros Días, I. de (coords.), $O$ jogo do Mundo. Lisboa: Instituto de Estudos de Literatura e Tradição, Faculdade de Ciências Sociais e Humanas, Universidade NOVA de Lisboa, 433-454.

(2018). Un aroma corrompido. En: A instancia de parte y dos obras más, de Mercedes Formica. Sevilla: Renacimiento (Espuela de Plata), 9-28.

(2020a). Olvidar no es sinónimo de traición. En: Pequeña historia de ayer (Memorias), de Mercedes Formica. Sevilla: Renacimiento, 7-45.

. (2020b). Feminismo, igualdad, franquismo: el desafío de Mercedes Formica en la búsqueda de una nueva identidad femenina. En: Fernández Ulloa, T. y Soler Gallo, M. (eds.), Aproximaciones a la configuración de la identidad en la cultura y sociedad hispanas e italianas contemporáneas. Madrid: Liceus, 89-108.

TRAPIELLO, A. (2019). Las armas y las letras: literatura y Guerra Civil (1936-1939). Barcelona: Destino.

VV. AA. (1965, julio-agosto). La generación española de 1936. Ínsula, 224-225. 
